\title{
Enterprise E-Learning Success Factors: An Analysis of Practitioners' Perspective (with a Downturn Addendum)
}

\author{
Eyal Sela \\ The Open University of \\ Israel, Raanana, Israel \\ eyalsela10@gmail.com
}

\author{
Yesha Y. Sivan \\ Metaverse Labs Ltd. and \& \\ Shenkar College, Ramat Gan, \\ Israel
}

yesha@metaverse-labs.com

\begin{abstract}
This study proposes nine success factors for enterprise-wide e-learning. These factors were derived from the literature, interviews with e-learning project leaders, and analysis. Twelve semistructured interviews were conducted and analyzed in order to find out the best success factors to implement e-learning. These factors are divided into two categories: "must-have" factors and "nice-to-have" factors. The must-have factors include: useful and easy to use e-learning tools, marketing, management support, the right organizational culture, and the existence of a real need for the organization. The "nice to have" factors include: time to learn, support, mandatory learning, and incentives. Based on the research conclusions, a checklist of e-learning success factors is provided. A special addendum includes looking at the factors in downturn times, their relative importance and nature.
\end{abstract}

Keywords: e-learning, success factors, implementation, employee training.

\section{Review}

"E-learning" describes the ability to electronically transfer, manage, support, and supervise learning and learning materials (Govindasamy 2002; Imamoglu, 2007; Normark \& Cetindamar, 2005). It allows organizations to train and develop employees. Cost savings, learning flexibility, better retention, unified and updated information and the ability to provide safe and easy to manage learning environments are just some of the advantages e-learning provides (Dagada \& Jakovljevic, 2004; Kathawala \& Wilgen, 2004; Macpherson, Eliot, Harris, \& Homan, 2004; Rabak \& Cleverand-Innes, 2006).

Material published as part of this publication, either on-line or in print, is copyrighted by the Informing Science Institute. Permission to make digital or paper copy of part or all of these works for personal or classroom use is granted without fee provided that the copies are not made or distributed for profit or commercial advantage AND that copies 1) bear this notice in full and 2) give the full citation on the first page. It is permissible to abstract these works so long as credit is given. To copy in all other cases or to republish or to post on a server or to redistribute to lists requires specific permission and payment of a fee. Contact Publisher@InformingScience.org to request redistribution permission.
In today's competitive environment (Kathawala \& Wilgen, 2004), workbased training and learning are critical. They enable organizations to keep up with the fast-changing world (Normark \& Cetindamar, 2005; Wellman, 2007).

A typical e-leaning project is at the intersection of two error-prone domains: Information Systems (IS) and human systems. A 2003 Hackett Group study

\section{Editor: Alex Koohang}

An earlier, shorter version of this paper was presented at the Chais conference 2009, in Raanana, Israel, and included in Y. Eshet-Alkalai, A. Caspi, S. Eden, N. Geri, \& Y. Yair (Eds.), Proceedings of the Chais conference on instructional technologies research 2009: Learning in the technological era. Raanana: The Open University of Israel. http://www.openu.ac.il/research center eng/conferences.html 
reported that $30 \%$ of Information Systems projects fail (Brown, Chervany, \& Reinicke, 2007). Elearning, being an information system, suffers even higher failure rates (Hogarth \& Dawson, 2008). These high failure rates indicate the existence of misconceptions regarding the implementation process and use of e-learning.

Our goal in this paper is to identify enterprise e-learning success factors. We hope to deepen the theoretical and practical understanding of e-learning implementation and recognize mandatory aspects to be considered in this process. This, in turn, will lessen failure rates and help make elearning more effective. A side benefit of this work may help designing of new learning tools, especially when it comes to virtual worlds, which is of special interest to the authors.

\section{Methodology}

To arrive at the enterprise e-learning success factors we used a combination of analytic work and qualitative interviews with practitioners (as depicted in Table 1).

Table 1. Research methodology

\begin{tabular}{|l|l|}
\hline Step & Description \\
\hline 1. Literature review & $\begin{array}{c}\text { To identify e-learning success factors we reviewed: } \\
\text { Corporate e-learning and higher education e-learning } \\
\text { literature; and } \\
\text { Technology-acceptance literature. }\end{array}$ \\
\hline $\begin{array}{l}\text { 2. Construction of a } \\
\text { semi-structured } \\
\text { interview }\end{array}$ & $\begin{array}{l}\text { Based on the literature review, a semi-structured interview was con- } \\
\text { structed. A semi-structured interview is suitable for the exploration } \\
\text { of perceptions and opinions about complex and sensitive issues } \\
\text { (Barriball, 1994), as well as for detection of ideas and general topics } \\
\text { allowing for future investigation (Macpherson et al., 2004). }\end{array}$ \\
\hline 3. Interviews & $\begin{array}{l}\text { 12 participants (out of 19 initially identified) from 11 companies in } \\
\text { various industries were interviewed. Participants were e-learning } \\
\text { project leaders ("Practitioners") identified in training websites or } \\
\text { recommended by other personal links. } \\
\text { All participants were from big companies (hundreds to thousands of } \\
\text { employees) that had been using e-learning for one and a half years } \\
\text { to more than a decade. Interviews ranged from 40 to 90 minutes. }\end{array}$ \\
\hline 4. Findings analysis & $\begin{array}{l}\text { Success factors were validated and additional ones were identified } \\
\text { via a qualitative analysis conducted by the authors. }\end{array}$ \\
\hline 5. Discussion & $\begin{array}{l}\text { Research findings and analysis were discussed and conclusions } \\
\text { were made. Conclusions were assembled into a checklist of e- } \\
\text { learning success factors. }\end{array}$ \\
\hline
\end{tabular}

From a methodology point of view we need to note that the interviews (and their qualitative analysis) are unstructured and sensitive to interviewer and interviewee biases. Therefore, it is less objective than other research methods. The small number of interviews made (12) as well as the use of convenience sample decreases external validity. 


\section{Findings}

Results are divided into two categories: "Must-have" factors and "Nice-to-have" factors (see Table 2.). Must-have factors are those undisputed, widely agreed upon. They must be part of the implementation. Nice-to-have factors appeared to be inconclusive among interviewees. Although they should be considered, they are more context related.

Table 2. E-learning success factors checklist

\begin{tabular}{|c|c|c|}
\hline Factor name & Factor Goal & Implementation \\
\hline \multicolumn{3}{|c|}{ "Must have" factors } \\
\hline \multirow{6}{*}{$\begin{array}{l}\text { 1. Usefulness and } \\
\text { Ease of use }\end{array}$} & \multirow{6}{*}{$\begin{array}{l}\text { Improve perceived ease of use } \\
\text { by learners; } \\
\text { Engaging employees. }\end{array}$} & User interface and instructional design experts. \\
\hline & & \begin{tabular}{|l} 
Learner centered design (easy navigation, no cognitive load). \\
.
\end{tabular} \\
\hline & & Avoid "over-abilities." \\
\hline & & Short course duration: 15 minutes up to one hour. \\
\hline & & Relevant and directly related to daily life learning materials. \\
\hline & & Communicate personal benefits. \\
\hline \multirow[b]{2}{*}{ 2. Marketing } & \multirow{2}{*}{$\begin{array}{l}\text { Understanding the rationale } \\
\text { behind company-wide e- } \\
\text { learning; } \\
\text { Awareness to e-learning tools; } \\
\text { Branding. }\end{array}$} & Emails, electronic brochures, teasers, portal, videos, conferences. \\
\hline & & Take advantage of important events (e.g. new product). \\
\hline \multirow{3}{*}{$\begin{array}{l}\text { 3. Management } \\
\text { support }\end{array}$} & \multirow{3}{*}{$\begin{array}{l}\text { Give mangers tools to assist } \\
\text { employees; } \\
\text { Get management support; } \\
\text { Change organizational culture. }\end{array}$} & Explain the relation to business goals. \\
\hline & & Guide managers. \\
\hline & & Emphasize positive outcomes and success stories. \\
\hline \multirow{4}{*}{$\begin{array}{l}\text { 4. Organizational } \\
\text { culture }\end{array}$} & \multirow{4}{*}{$\begin{array}{l}\text { Learning culture; } \\
\text { Taking responsibility for one's } \\
\text { learning; } \\
\text { Change studying habits. }\end{array}$} & Make employees' competency an organizational measure. \\
\hline & & Disseminate success stories. \\
\hline & & $\begin{array}{l}\text { Prevent alternatives (offer learning materials with no other teach- } \\
\text { ing solutions). }\end{array}$ \\
\hline & & Explain employees the new concept, its goals and future planning. \\
\hline \multirow{2}{*}{ 5. Real need } & \multirow{2}{*}{$\begin{array}{l}\text { Identifying a real need for the } \\
\text { organization. }\end{array}$} & Use "field agents" before and while developing e-learning. \\
\hline & & \begin{tabular}{|l} 
Relay on constitutive event (e.g. enterprise-wide implementations). \\
.
\end{tabular} \\
\hline \multicolumn{3}{|c|}{ "Nice to have" factors } \\
\hline \multirow{3}{*}{ 1. Time to learn } & \multirow[b]{2}{*}{ Allocation of learning time. } & Guide managers to allow and offer learning during work hours. \\
\hline & & $\begin{array}{l}\text { Make e-learning a routine or allocate time as part of company } \\
\text { policy. }\end{array}$ \\
\hline & $\begin{array}{l}\text { Or Helping employees choose } \\
\text { their own study times. }\end{array}$ & $\begin{array}{l}\text { Or Make sure managers allow learning during work hours and that } \\
\text { materials are relevant to employees' own work interests. }\end{array}$ \\
\hline 2. Support & $\begin{array}{l}\text { Higher confidence; } \\
\text { Prevent dropouts. }\end{array}$ & $\begin{array}{l}\text { If necessary: } \\
\text { Provide support / only during implementation / No support. } \\
\text { (Technical - how to use, guidance - explain the learned material, } \\
\text { and peers support). }\end{array}$ \\
\hline
\end{tabular}




\begin{tabular}{|c|c|c|}
\hline Factor name & Factor Goal & Implementation \\
\hline \multirow{3}{*}{$\begin{array}{l}\text { 3. Mandatory } \\
\text { usage }\end{array}$} & \multirow{3}{*}{ Enforcing e-learning. } & Offer only learning materials with "owners" that enforce learning. \\
\hline & & Integrate e-learning into company policies. \\
\hline & & Do not develop optional learning contents. \\
\hline \multirow{5}{*}{ 4. Incentives } & \multirow{2}{*}{$\begin{array}{l}\text { Extrinsic motivation; } \\
\text { Recognition. }\end{array}$} & Certificates, continuing education credits, personal record. \\
\hline & & Recognition posting on bulletin boards, contests, quizzes. \\
\hline & \multirow{3}{*}{$\begin{array}{l}\text { Or intrinsic motivation; Posi- } \\
\text { tive experience. }\end{array}$} & $\begin{array}{l}\text { Or Pay heed to physical attributes: visualization, interactive, col- } \\
\text { orful, feedback users }\end{array}$ \\
\hline & & Offer learning materials that are unavailable otherwise. \\
\hline & & Communicate the contribution to personal development. \\
\hline
\end{tabular}

\section{"Must-have" Factors}

In this section we further explicate on the factors as they relate to prior state of the art.

Perceived usefulness and ease of use - According to the Technology Acceptance Modal (TAM), there are two determinants of new technology acceptance: perceived usefulness - "the degree to which a person believes that using a particular system would enhance his or her job performance" (Davis, as cited in Venkatesh, Morris, Davis, \& Davis, 2003), and perceived ease of use - "the degree to which a person believes that using a particular system would be free of effort" (Davis, as cited in Venkatesh et al., 2003). Lee (2006) validated the extension of the modal on e-learning.

Some interviewees said ease of use is extremely important. Others regarded it as taken for granted. They added that e-learning should be "learner-centered" rather than "learning-centered." For example, it has been recommended not to test too much and to keep courses short.

It is critical that employees understand the relation to their daily work and personal benefit. Perceived usefulness should be considered when choosing learning materials and as part of the marketing program.

Marketing - Marketing is an integral part of an e-learning implementation (Macpherson et al., 2004; Masie, 2001). It helps create a "critical mass" of users (Lee, 2006), prevent user resistance (Chen \& Hsiang, 2007), and raise the awareness to the tool and its benefits.

Some have supported intensive marketing while others claimed marketing should be used only to the extent where employees are aware of e-learning tools available. Advertising techniques mentioned were emails, electronic brochures, teasers, portal, videos, conferences, and more.

Management support - As with other information systems (Neumann, 1998), management support is critical to e-learning implementation (Morison, 2003). Macpherson et al. (2004) mention top management's consistency and vocal support as a key to success. Masie (2001, p.4) notes that "The role of the manager as an overt champion of the learner's development must be extended to e-learning offerings."

Management support is one of the most important factors reported. The top management support was mentioned as important due to the organization-wide change required. The direct management support importance is due to their ability to influence employees. Direct managers are more familiar with employees. They are able to guide and direct. They can assist employee in finding the right time to learn and by that support acceptance of the new technology and the process.

Organizational culture - Developing organizational culture that encourages e-learning use is one of Masie's (2001) recommendations. The right organizational culture is necessary for several reasons: 
- Employees' resistance to using technology instead of face-to-face learning (Macpherson et al., 2004 ; "Savvy employers," 2001). We estimate the sheer "fear" of common technology will no longer be a factor as it becomes an integral part of our lives.

- Overcoming a legacy of prior experience and old values and norms (Macpherson et al., 2004).

- Making people understand how to 'e-learn'.

- Convincing managers to encourage and support employees to study rather than discourage them from doing so (Morison, 2003), and more.

Our interviewees explained that most people are used to face-to-face, instructor-lead training. At times the new method is unnatural to them. It requires different skills and abilities from the ones required so far. Thus, a profound change in their studying habits, as well as overcoming some "mental barriers," is essential.

Cultural change could be done directly, by disseminating e-learning success stories and explaining to employees and their managers the new concept and its goals. Or, it could be done indirectly, by defining employees' competency as an organizational measure. This, in turn, will get managers more motivated to train their workers and encourage them to use e-learning (especially if there are no alternatives).

A real need for the organization - Seven of our interviewees mentioned that the base to elearning use in the organization has to be a "no other alternative" one (e.g. other alternatives are too expensive, difficult to implement, or very inefficient). This factor was not identified in the literature review.

\section{"Nice-to-have" factors}

Time to learn - researchers recommend scheduling and providing time to learn during company time (Masie, 2001; Normark \& Ctindamr, 2005; Rabak \& Cleveland, 2006). This is mainly due to a work load that prevents employees from doing "extras" such as e-learning.

Seven interviewees said e-learning was more effective when learning is actively scheduled by managers. As opposed to that, others said that if employees find a personal interest and benefit or have their manager's support, they will be able to find their time to study by themselves.

Support - Masie (2001), as well as Macpherson et al. (2004) and Selim (2007), found that the provision of technical support (how to use), guidance (by instructor), and peer support had a positive effect on the willingness to use and the actual participation in e-learning. Lee (2006) and Carter and Bélanger (2005) found that the support increased the perceived ease of use.

Those in favor of e-learning support explained that the mere knowledge of the fact that they have someone to help them reassures learners and prevents negative attitudes and dropouts. On the other hand, some claimed support to be unnecessary and even said the need for support to be a quality issue (namely, poor e-learning systems need more support).

Mandatory usage - Both Lee (2006) and Govindasamy's (2002) studies implicate that mandatory usage (vs. voluntary) is necessary and can increase e-learning effectiveness. Nevertheless, mandatory usage does not guarantee $100 \%$ participation (Masie, 2001).

While four interviewees said e-learning should be voluntary based, five objected, saying that usage would drop in such a case. Mandatory usage supporters often said that non-obligatory learning material should not be offered. 
Incentives to use e-learning - Normark and Cetindamar (2005) found that incentives had encouraged employees to use e-learning. Other studies support this assumption (Macpherson et al., 2004; McPherson \& Nunes, 2006). Masie (2001, p.2) recommends use of "incentives beyond candy bars and meaningless certificates that provide valuable benefits such as career advancement and peer recognition."

Our interviewees suggested using material incentives such as certifications, continuing education programs, personal file records, or promotion preconditions. Others opposed that idea. They worried that material incentives might become the sole reason for using e-learning. Thus, they suggested only using nonmaterial ones, such as peer recognition.

Even though most interviewees believed it is pointless to rely on the learner's intrinsic motivation, some claimed it is complementary to external incentives. Employees must understand the added value of e-learning (such as the ability to learn materials that are unreachable in other ways).

\section{Discussion and Recommendations}

When implementing e-learning, a holistic approach has to be taken. We should consider different aspects, such as technological issues, design, users support, subject matter, incentives, and culture.

Transforming "learning" into "e-learning" is not just about developing online courses. More factors should be taken into account ("must-haves"): useful and easy to use e-learning tools, the existence of a real need for the organization, direct and executive management support, marketing, and an organizational culture that supports and encourages learning, and especially elearning.

Five factors (four identified in the literature review and one that was not mentioned and emerged as critical - a real need for the organization), have been found important and undisputed to elearning success. The remaining four factors were controversial and inconclusive among interviewees.

The inconclusive factors ("nice-to-have") - mandatory learning, scheduling, and providing time to learn, support, and incentives - might depend on contextual factors such as an organization's culture, its population, or e-learning content. Nevertheless, we should bear them in mind and understand when and how they affect e-learning success, as well as how to leverage them in our favor.

Complexity decreases usage. Therefore, "over-abilities" should be avoided. By identifying a "real need" for the organization (an action that could be supported by consulting "field agents"), a suitable e-learning program could be implemented more easily.

We cannot expect employees to use e-learning just because it's there. E-learning won't sell itself even if learning materials offer personal growth and effectiveness. The values of the specific elearning program should be communicated. Marketing might include face-to-face instruction, conferences, and/or e-newsletters. Moreover, it should take advantage of important events (such as enterprise-wide software implementation) and have a strong and clear connection to employees work.

E-learning tools should be learner focused (simple, easy to use, not overwhelming, and familiar to users) and developed by experienced professionals. External incentives such as certifications, continuing education credit, and peer recognition should be considered as well as internal incentives such as enjoyable and attractive physical attributes and e-learning materials that are unavailable in other ways. 
Sometimes (but not always) more extreme steps have to be taken: mandatory use. In these cases, e-learning usage has to be integrated into corporate policies or be developed only if learning materials have "owners" that will enforce studying.

Training, once an interpersonal process, has become a one person (and one computer) process. This radical change requires adjustments to the organizational culture and a new thinking about the role of computers as part of organization life. If managers understand e-learning's benefits for them and for their subordinates, they will help to create an e-learning supportive culture. Furthermore, they will assist employees to find time to use it or proactively schedule this time for them.

By identifying important success factors, this research enables new, as well as more experienced e-learning project leaders, to have higher chances to succeed in e-learning implementation and use in their organization.

The findings and recommendations should be further validated via a quantitative research. Examination of the relation between fixed organizational factors (e.g. resources, industry) and success factors found in this research will be of most use.

\section{Addendum: The Factors at Downturn}

2009 seems to bring yet another recession. Companies worldwide are struggling to maintain customers, lower prices, and relative pressures. In such times, new projects in general and in learning are often being postponed for better times. Yet, in other cases, circumstances call for learning. This could be the introduction of a new product, the shifting of job skills due to mergers and acquisitions, going into new fields (e.g., moving from web based computing to mobile computing), etc. The goal of this addendum is to look at the factors, their relative importance, and changing nature in downturn. Importance will be noted as More, Same, and Less.

\section{"Must have" factors}

1. Usefulness and Ease of use - Same - people still want to make good use of their time. While they are open to new experiences in such times, it is still critical for them to feel the value of the e-learning experience.

2. Marketing - More - In such times, people often ask if such investment makes sense. We need to make sure that the actual value is known.

3. Management support - Same - people are even more tuned to what management is saying, as they have more time to listen, and greater fear of risk. Management support should be clear and relevant to internal and external conditions.

4. Organizational culture - More - such times, especially if the firm is hit hard may call for changes in culture. At some firms, the impact of this factor on e-learning will change per the culture. Overall, more attention is needed here.

5. Real need - Same - on the one hand people are more open to learning. On the other hand the need must be communicated both in terms of the learners and the firm.

\section{"Nice to have" factors}

1. Time to learn - Less - people may have less day to day work and more time to learn. They may also have more personal time due to the need to keep their job.

2. Support - Same - while people may not complain as much in downturn they still suffer. Learning is being hampered with malfunctioning computers, software, and other systems. 
3. Mandatory usage - Less - at such times, people are more likely to jump upon opportunities to learn.

4. Incentives - Less - while always good, there is less need for financial incentives. Other incentives will be appreciated.

In conclusion, downturn times are both a risk and an opportunity for e-learning. The above cursory analysis demonstratse again the difference between "Must have" and "Nice to have" factors (as the impact of must have factors is more critical at downturn.). Naturally each organization, and the e-learning leader, should adapt their e-learning program to the internal and external conditions. It is our hope that these factors will serve as a checklist to such adaptations.

\section{Acknowledgements}

This paper was expanded from a seminar paper written by Eyal Sela in the course Strategic Information Systems, instructed by Gil Bickel, at The Open University of Israel, the Department of Management and Economics. The seminar paper has been written under the supervision of Dr. Yesha Sivan.

\section{References}

Barriball, K. L., \& While, A. (1994). Collecting data using semi-structured interviews: A discussion paper. Journal of Advanced Nursing, 19, 328-335.

Brown, S. A., Chervany, N. L., \& Reinicke, B. A. (2007). What matters when introducing new information technology. Communications of the ACM, 50(9), 91-96.

Carter, L., \& Bélanger, F.(2005). The utilization of e-government services: Citizen trust, innovation and acceptance factors. Information Systems Journal, 15(1), 5-25.

Chen, R. S., \& Hsiang, C. H. (2007). A study on the critical success factors for corporations embarking on knowledge community-based eLearning. Information Sciences, 177, 570-586.

Dagada, R., \& Jakovljevic, M. (2004). Where have all the trainers gone? E-learning strategies and tools in the corporate training environment. Presented at SAICSIT, Pretoria, South Africa.

Govindasamy, T. (2002). Successful implementation of e-learning: Pedagogical considerations. Internet and Higher Education, 4(3-4), 287-299.

Hogarth, K., \& Dawson, D. (2008). Implementing e-learning in organisations: What e-learning research can learn from instructional technology (IT) and organisational studies (OS) innovation studies. International Journal on E-Learning, 7(1), 87-105.

Imamoglu, S. Z. (2007). An empirical analysis concerning the user acceptance of e-learning. Journal of American Academy of Business, 11(1), 132-137.

Kathawala, Y., \& Wilgen A. (2004). E-learning: Evaluation from an organization's perspective. Training \& Management Development Methods, 18(4), 1-13.

Lee, Y. (2006). An empirical investigation into factors influencing the adoption of an e-learning system. Online Information Review, 30(5), 517-541.

Macpherson, A., Eliot, M., Harris, I., \& Homan,G. (2004). E-learning: Reflections and evaluation of corporate programmes. Human Resource Development International, 7(3), 295-313.

Masie, E. (2001). E-learning: "If we build it, Will they come?" The Masie Centre and ASTD Report, ASTD, Alexandria, VA.

McPherson, M., \& Nunes, M. B. (2006). Organizational issues for e-learning: Critical success factors as identified by HE practitioners. The International Journal of Educational Management, 20(7), 542-558. 
Morrison, D. (2003). E-Learning strategies: How to get implementation and delivery right first time. New York, NY, USA: John Wiley \& Sons.

Normark, O. R., \& Cetindamar, D. (2005). E-learning in a competitive firm setting. Innovations in Education \& Teaching International, 42(4), 325-335.

Neumann, Z. (1998). Strategic information systems: Competition through information technologies. TelAviv, Israel: The Open University of Israel (in Hebrew).

Rabak, L., \& Cleveland-Innes, M. (2006). Acceptance and resistance to corporate e-learning: A case from the retail sector. Journal of Distance Education, 21(2), 115-134.

Savvy employers make e-learning part of their overall training strategy. (2001). IOMA's Human Resource Department Management Report, 1, 6-8.

Selim, H. M. (2007). Critical success factors for e-learning acceptance: Confirmatory factor models. Computers \& Education, 49(2), 396-413.

Venkatesh, V., Morris, M. G., Davis, G. B., \& Davis, F. D. (2003). User acceptance of information technology: Toward a unified view. MIS Quarterly, 27(3), 425-478.

Wellman, J. (2007). Lessons learned about lessons learned. Organization Development Journal, 25(3), 6572 .

\section{Biographies}

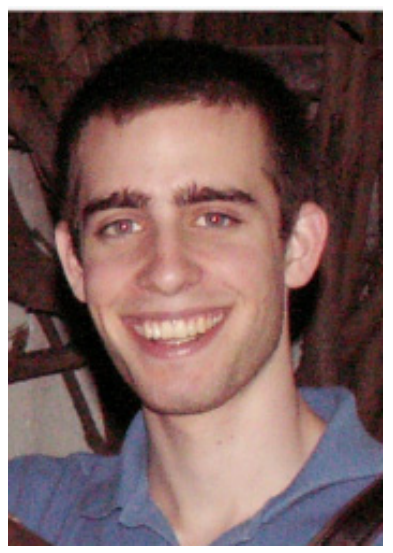

Eyal Sela is a project manager at The Israeli Chapter of the Internet Society (ISOC-IL). He writes about productivity, social media and internet at his blog http://www.productivewise.com as well as at the technology blog http://www.makeuseof.com. Eyal received his Business Management B.A from The Open University of Israel.

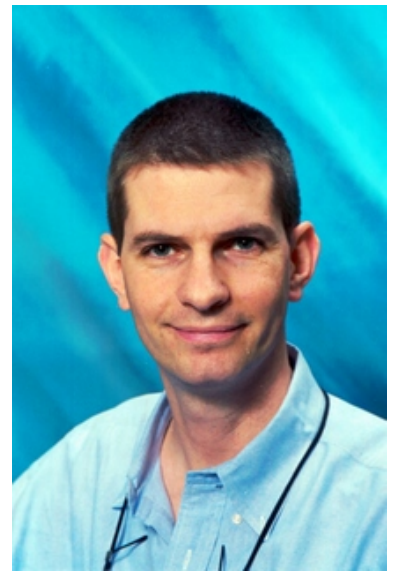

Dr. Yesha Sivan is a senior lecturer at the Department of Software Engineering, Shenkar College of Engineering and Design. He is also the founder of Metaverse Labs (MVL) - a leading think tank focusing on linking virtual and real worlds. Dr. Sivan is a pioneer and leader of technologies for knowledge infrastructures. His professional experience in the development of innovative workplaces for corporate, hitech, government, military and defense environments (e.g., the Harvard 9-Keys for Knowledge Infrastructure). Dr. Sivan received his doctorate from Harvard University, and is a research affiliate in Harvard's Program on Information Resources Policy; he was the entrepreneur-inresidence (EIR) in JVP Venture Fund Studio. He is teaching Metaverse related courses in Afeka College of engineering, Tel Aviv University

School of Computer Sciences, and Bar-Ilan University Executive MBA Program. His alter person is Dera Kit, and his blog is http://www.dryesha.com. He published numerous papers in the areas of knowledge, virtual worlds, and standards. His latest book about Virtual Worlds is called "Your Next World: Second Life as an introduction to the Metaverse." 